\title{
Synthesis and Characterization of Ordered Intermetallic PtPb Nanorods
}

Sean Maksimuk, Shengchun Yang, Zhenmeng Peng, and Hong Yang*

Department of Chemical Engineering, University of Rochester, 206 Gavett Hall, Rochester, New York 14627

Supporting Information

\section{Synthesis and Characterization of PtPb nanorods}

$\mathrm{PtPb}$ nanorods were synthesized using the standard Schlenk line technique under argon atmosphere. Specifically, $40 \mathrm{mg}$ of platinum acetylacetonate ( $\mathrm{Pt}(\mathrm{acac})_{2}$, Aldrich), $40 \mathrm{mg}$ of lead acetylacetonate $\left(\mathrm{Pb}(\mathrm{acac})_{2}\right.$, Aldrich), $216 \mathrm{mg}$ of 1-adamantanecarboxylic acid (ACA, 99\%, Aldrich), $2 \mathrm{~g}$ of hexadecylamine (HDA, 90\%, Aldrich), $1.11 \mathrm{~mL}$ of hexadecanethiol (HDT, 95\%, Fluka), and $1 \mathrm{~mL}$ of diphenyl ether (DPE, 99\%, Aldrich) were mixed in a $25 \mathrm{~mL}$ three-neck round-bottom flask. The flask was evacuated and purged with argon for several times, before it was immersed into an oil bath set at $180{ }^{\circ} \mathrm{C}$. The mixture gradually turned into a transparent orange color. After the temperature of oil bath stabilized, $51 \mathrm{mg}$ of tert-butylamine borane complex (TBAB) was injected into the flask and the mixture immediately turned black, indicating the formation of nanocrystals. The reaction was kept at $180{ }^{\circ} \mathrm{C}$ for $30 \mathrm{~min}$ after the injection of TBAB. The as-synthesized materials contained minor small particles of other shapes, which were separated out by size selective precipitation. In a typical procedure, about $4 \mathrm{~mL}$ of the final product mixture was washed with a solvent containing $8 \mathrm{~mL}$ of chloroform and $10 \mathrm{~mL}$ of ethanol and then centrifuged at 12,000 rpm for $2 \mathrm{~min}$. After the centrifuge, the supernatant was decanted and the precipitate was dispersed in $18 \mathrm{~mL}$ of the same type of chloroform and methanol mixed solvent. The resultant suspension was centrifuged at 6,000 rpm for 4 min and the supernatant was decanted. This centrifuge procedure was repeated three more times to purify the nanorods. In order to remove the by-products, the precipitate was dispersed in $12 \mathrm{~mL}$ of chloroform and ethanol solvent mixture and then centrifuged at 12,000 rpm for $4 \mathrm{~min}$. The chloroform to ethanol volumetric ratio was 8:1. After the centrifuge, the supernatant was collected in a vial and the precipitate was discarded. This supernatant was further concentrated to about $4 \mathrm{~mL}$ stepwise, at about 2-mL per step, by drying with argon and then centrifuged at 13,000 rpm for 10 min each step. The final product was stored in dry powder form and could be dispersed in chloroform or hexane for further characterization.

The powder X-ray diffraction (PXRD) spectra were recorded on a Philips MPD diffractometer with a $\mathrm{Cu} K_{\alpha} \mathrm{X}$-ray source $(\lambda=1.5405 \AA)$. The assignment of $\mathrm{PtPb}$ intermetallic phase was based on the JCPDS database-International Centre for Diffraction Data, 1999, PCPDFWIN v. 2.02. TEM specimens were prepared by drop-casting nanorod dispersions onto carbon-coated TEM grids. A JEOL JEM 2000EX operated at $200 \mathrm{kV}$ was used for TEM analysis and recording electron diffraction patterns. The HR-TEM images were recorded on a FEI TECNAI F-20 operated at $200 \mathrm{kV}$. Energy dispersive X-ray (EDX) spectroscopy was obtained with an EDAX detector installed on a fieldemission scanning electron microscope (FE-SEM, model: LEO 982).

\section{Electrochemical Characterization of PtPb nanorods}


Carbon black (Vulcan XC-72) was dispersed in hexane and sonicated for $1 \mathrm{~h}$. A known amount of $\mathrm{PtPb}$ nanorods were added to this dispersion at the nanorods to carbon black weight ratio of 20:80. This mixture was further sonicated for $30 \mathrm{~min}$ and stirred overnight. The resultant solids were precipitated out and dried under an argon stream. The $\mathrm{PtPb} / \mathrm{C}$ was then treated in air plasma for 30 min. This powder was then treated at $600{ }^{\circ} \mathrm{C}$ for $2 \mathrm{~h}$ under an atmosphere of $5 \%(\mathrm{v} / \mathrm{v})$ hydrogen in argon. The final product was dispersed in water at a concentration of $0.5 \mathrm{mg} \mathrm{PtPb} / \mathrm{mL}$. The final weight percent of $\mathrm{PtPb}$ on carbon black was determined by thermogravimetric analysis (TGA) using a SDT Q600 simultaneous TGA/DSC system from TA Instruments.

For the cyclic voltammetric measurements, ten microliters of $\mathrm{PtPb} / \mathrm{C}$ suspension was drop-cast onto a glassy carbon electrode and dried under a stream of air. The reference $\mathrm{PtRu} / \mathrm{C}$ catalyst was purchased from Johnson-Matthey and consisted of $30 \% \mathrm{Pt}$ and $15 \% \mathrm{Ru}$ by weight. The PtRu/C catalysts were dispersed in water at $0.5 \mathrm{mg} \mathrm{Pt} / \mathrm{mL}$ and $10 \mu \mathrm{L}$ of suspension was drop-cast onto the glassy carbon electrode.

For the methanol oxidation reaction, the concentrations were $0.5 \mathrm{M}$ for methanol and $0.1 \mathrm{M}$ for sulfuric acid. The scan rate was set at $50 \mathrm{mV} \mathrm{s}^{-1}$ and the $50^{\text {th }}$ cycle was recorded and presented in this work. An $\mathrm{Ag} / \mathrm{AgCl}(3 \mathrm{M} \mathrm{KCl})$ electrode was used as the reference and a platinum mesh was used as the counter electrode.

Table S1. Observed $d$-spacing from ED pattern, simulated $d$-spacing and relative intensity for PtPb intermetallics*

\begin{tabular}{|c|c|c|c|}
\hline lattice plane & $\begin{array}{c}\text { observed } d \text {-spacing } \\
\text { from ED pattern }\end{array}$ & calculated $d$-spacing ${ }^{2}$ & calculated relative intensity $^{2}$ \\
\hline$(100)$ & 3.68 & 3.67 & 19.03 \\
\hline$(101)$ & 3.06 & 3.05 & 86.61 \\
\hline$(002)$ & 2.74 & 2.74 & 0.03 \\
\hline$(102)$ & 2.20 & 2.20 & 100.00 \\
\hline$(110)$ & 2.12 & 2.12 & 81.59 \\
\hline$(201)$ & 1.73 & 1.74 & 17.70 \\
\hline$(103)$ & 1.63 & 1.64 & 14.54 \\
\hline$(202)$ & 1.52 & 1.53 & 32.47 \\
\hline$(004)$ & 1.36 & 1.37 & 6.90 \\
\hline
\end{tabular}

*: $\quad$ The computer software package JSV1.08lite ${ }^{1}$ was used to draw PtPb crystal structures and simulate electron diffraction patterns. PowderCell 2.4 was used to simulate the X-ray diffraction pattern. $^{2}$

\section{References}

(1) Weber, S. JSV1.08lite, http://jcrystal.com/steffenweber/JAVA/JSV/jsv.html

(2) Kraus, W.; Nolze, G. PowderCell, http://www.ccp14.ac.uk/tutorial/powdcell/index.html 


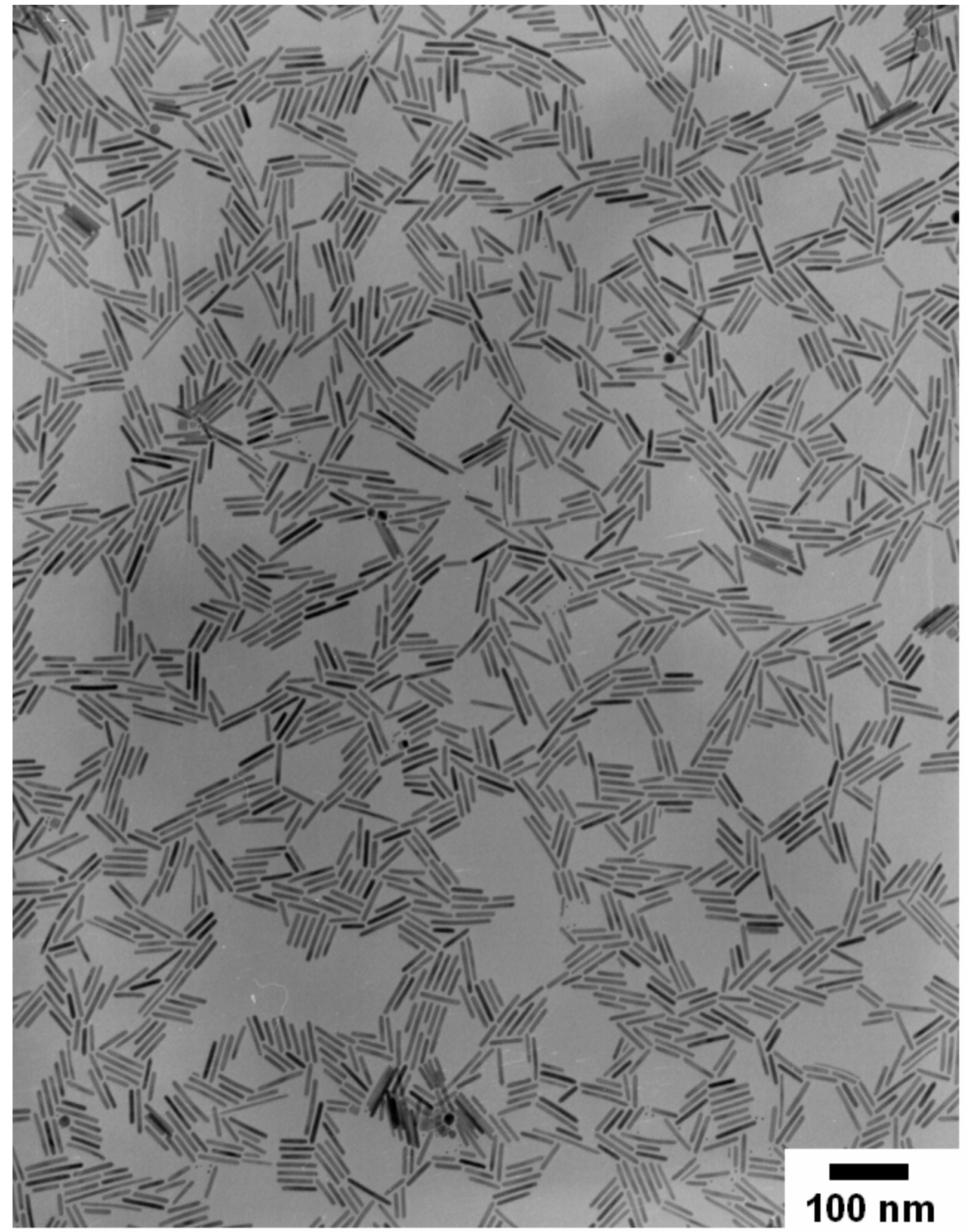

Figure S1. TEM image showing the large area of $\mathrm{PtPb}$ nanorods presented in Figure 1a. 


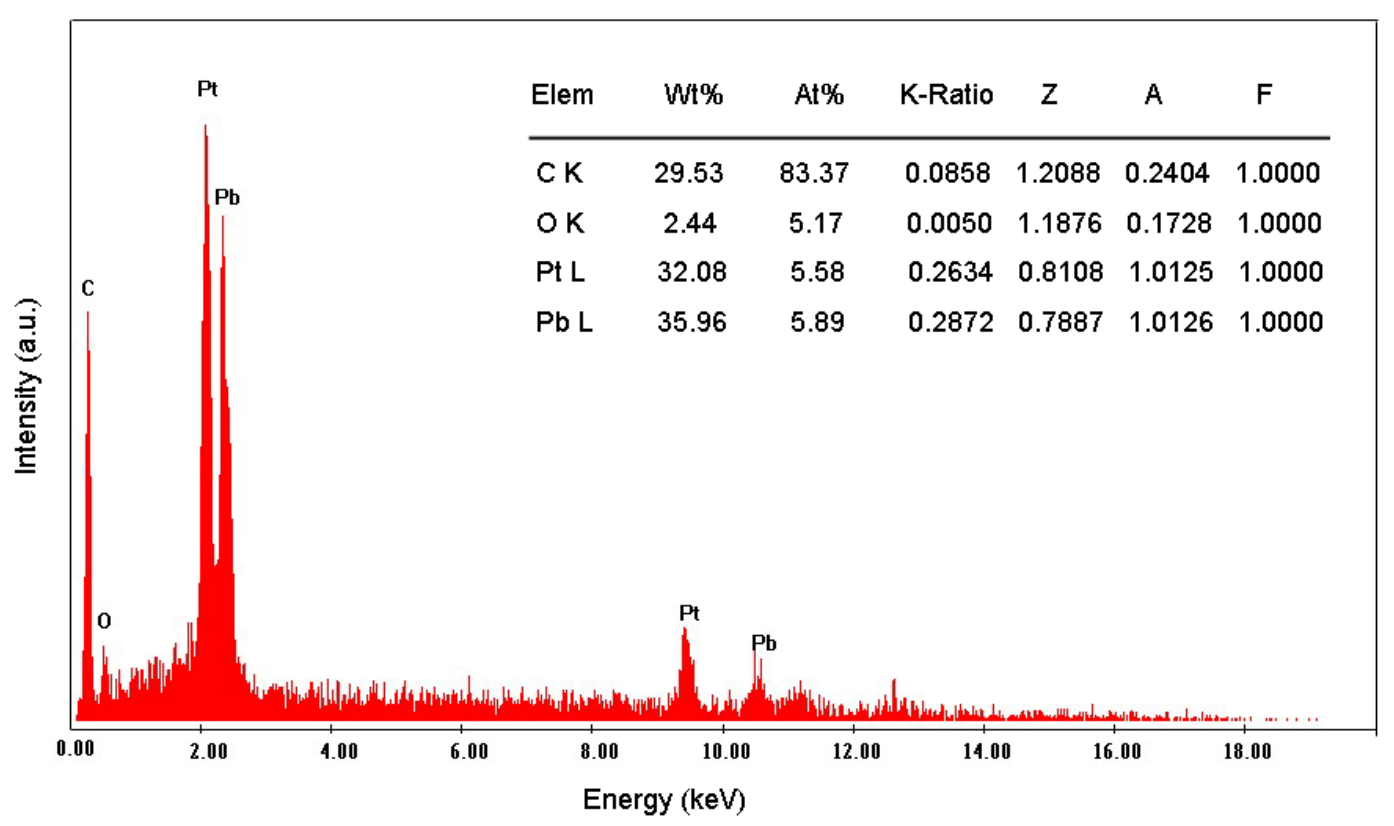

Figure S2. Energy dispersive X-ray (EDX) spectroscopy for as-synthesized PtPb nanorods showing the $\mathrm{Pt} / \mathrm{Pb}$ atomic ratio around 50/50.

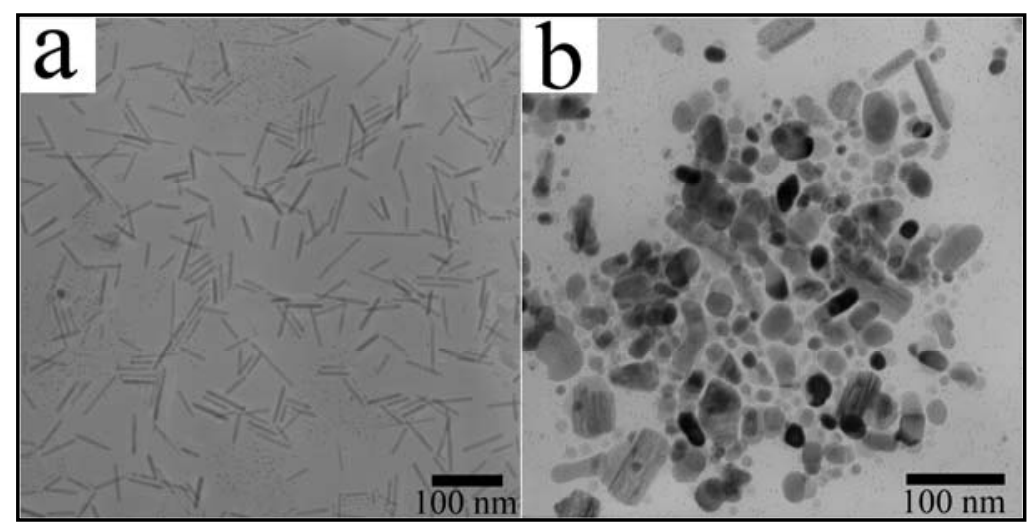

Figure S3. TEM images showing the effect of TBAB amount on the formation of PtPb nanorods. The amounts of TBAB used were (a) $51 \mathrm{mg}(0.6 \mathrm{mmol})$ and (b) $104 \mathrm{mg}(1.2 \mathrm{mmol})$. Other reagents and amounts used in this test were $\mathrm{Pt}(\mathrm{acac})_{2}$ (40 mg, $\left.0.1 \mathrm{mmol}\right), \mathrm{Pb}(\mathrm{acac})_{2}$ (40 mg, $\left.0.1 \mathrm{mmol}\right)$, ACA (216 mg, $1.2 \mathrm{mmol})$, HDA (2 g), HDT (1.11 mL, $3.6 \mathrm{mmol})$ and DPE (1.2 mL). The reaction time was 30 min and the temperature was $180^{\circ} \mathrm{C}$. 


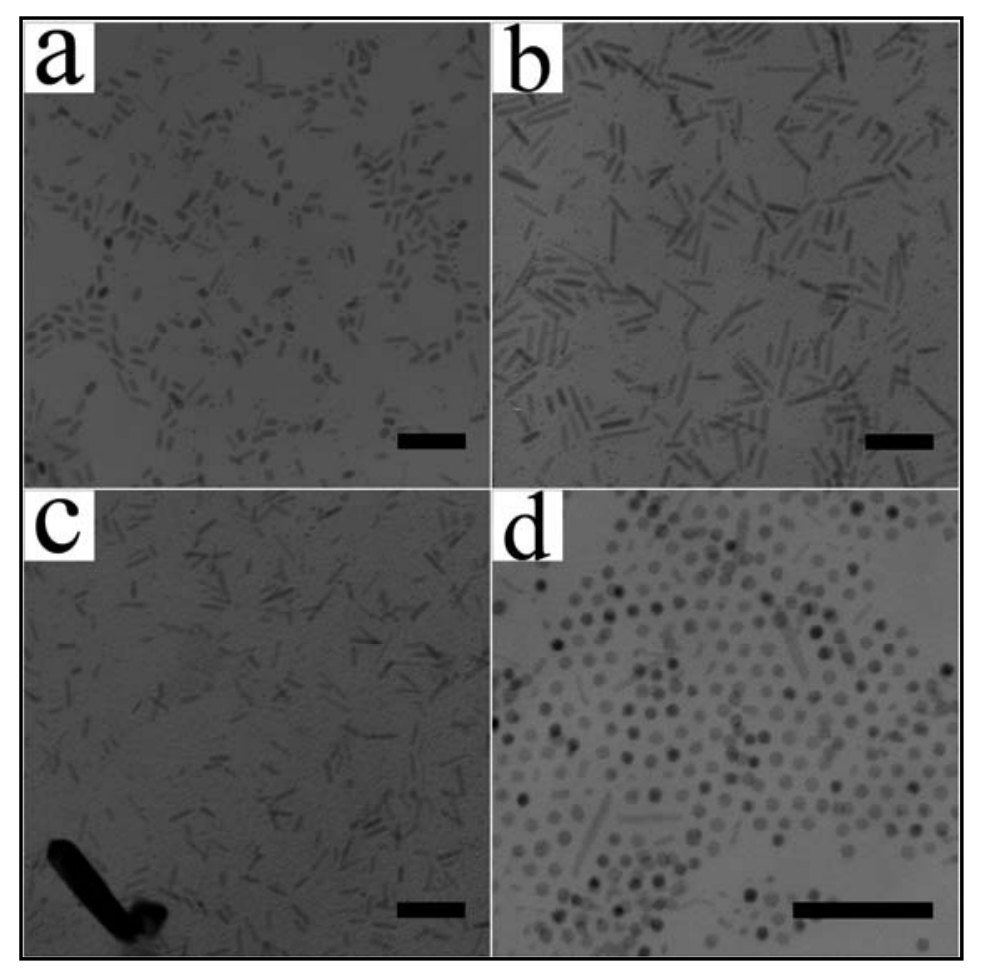

Figure S4. TEM images showing the effect of HDT amount on the formation of PtPb nanorods. The amounts of HDT used were (a) 555 (1.8 mmol), (b) 1110 (3.6 mmol), (c) 1863 (6 mmol) and $2220 \mu \mathrm{L}$ (7.2 mmol), respectively. The other reagents and amounts used were $\mathrm{Pt}(\mathrm{acac})_{2}$ (40 mg, $\left.0.1 \mathrm{mmol}\right)$, $\mathrm{Pb}($ aсас) 2 (40 mg, $0.1 \mathrm{mmol}$ ), ACA (216 mg, $1.2 \mathrm{mmol})$, HDA (2 g), TBAB (51 mg, $0.6 \mathrm{mmol}$ ) and DPE $(1 \mathrm{~mL})$. The reaction time was $30 \mathrm{~min}$ and the temperature was $180^{\circ} \mathrm{C}$. All scale bars are $50 \mathrm{~nm}$. 


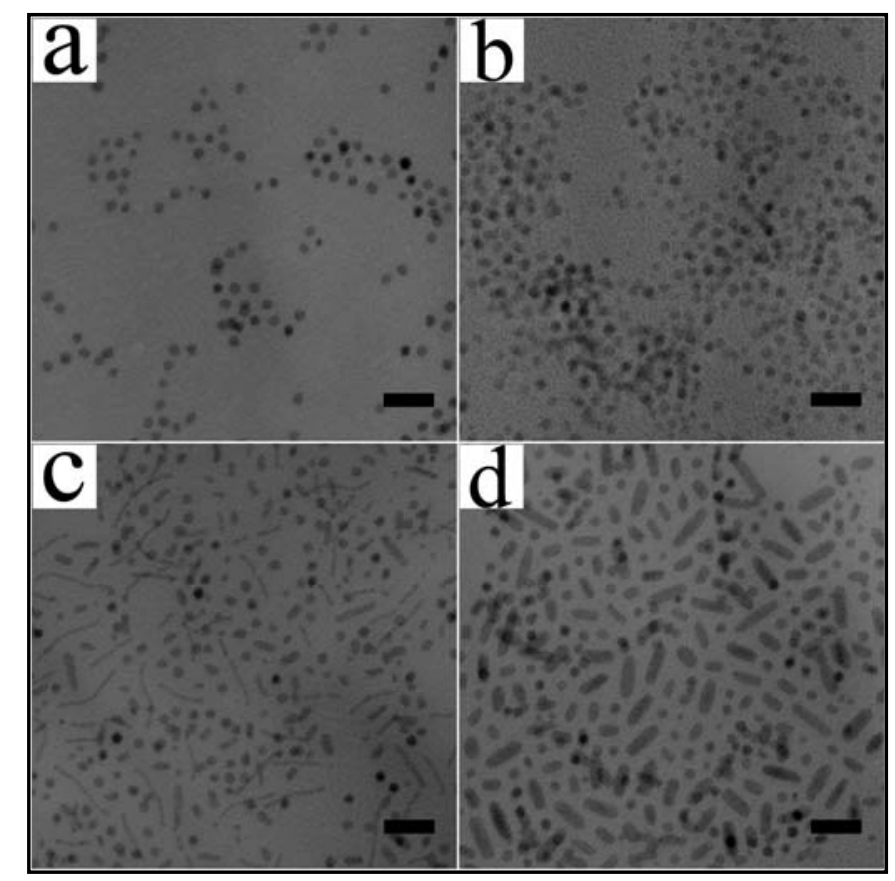

Figure S5. TEM images showing the effect of ACA and HDT amounts on the formation of PtPb nanorods. The amounts used were $432 \mathrm{mg}(2.4 \mathrm{mmol})$ of ACA and $2 \mathrm{~g}$ of HDA in (a, b) and $216 \mathrm{mg}$ (1.2 mmol) of ACA and $4 \mathrm{~g}$ of HDA in (c, d). The samples were taken out after reactions for (a, c) 30 and (b, d) $120 \mathrm{~min}$, respectively. The other reagents and amounts used were $\mathrm{Pt}(\mathrm{acac})_{2}$ (40 mg, 0.1 mmol), Pb(асас) 2 (40 mg, $0.1 \mathrm{mmol})$, TBAB (51 mg, $0.6 \mathrm{mmol})$, HDT (1.11 mL, $3.6 \mathrm{mmol})$ and DPE $(1 \mathrm{~mL})$. The reaction temperature was $180^{\circ} \mathrm{C}$. All scale bars are $20 \mathrm{~nm}$.

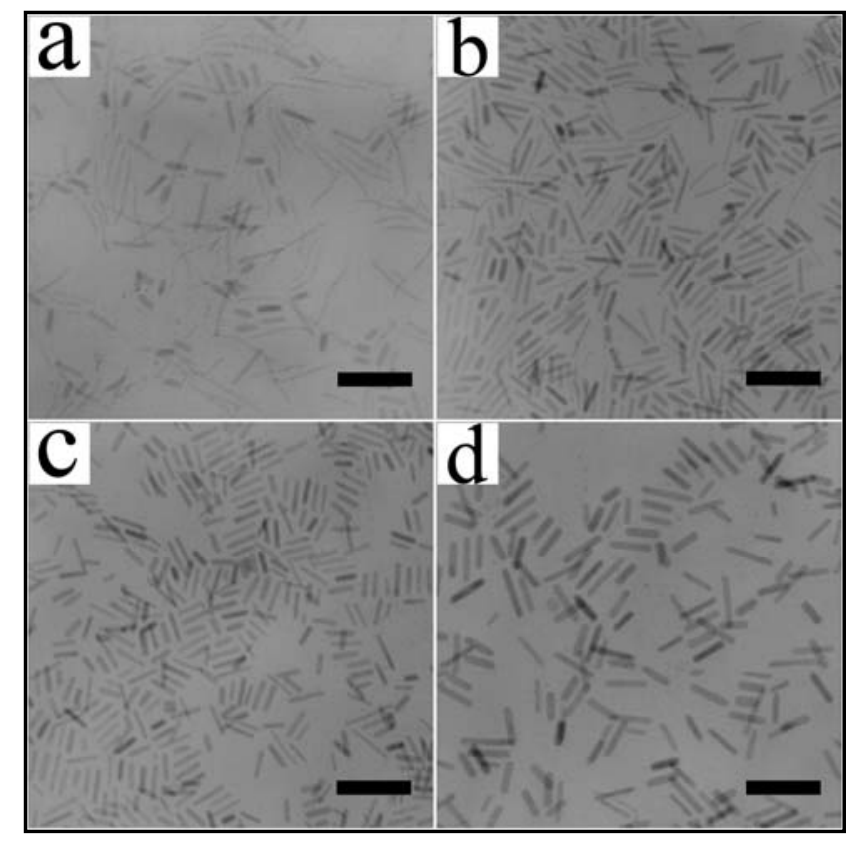

Figure S6. TEM images of PtPb nanorods synthesized at $180{ }^{\circ} \mathrm{C}$ for (a) 10, (b) 30, (c) 60 and (d) 120 min, respectively after TBAB was added. The reagents and amounts used in this test were Pt(acac) 2 (40 mg, $0.1 \mathrm{mmol}), \mathrm{Pb}(\mathrm{acac})_{2}$ (40 mg, $\left.0.1 \mathrm{mmol}\right)$, ACA(216 mg, $\left.1.2 \mathrm{mmol}\right)$, HDA (2 g), HDT (1.11 $\mathrm{mL}, 3.6 \mathrm{mmol})$, DPE (1.2 mL) and TBAB (51 mg, $0.6 \mathrm{mmol})$. All scale bars are $50 \mathrm{~nm}$. 


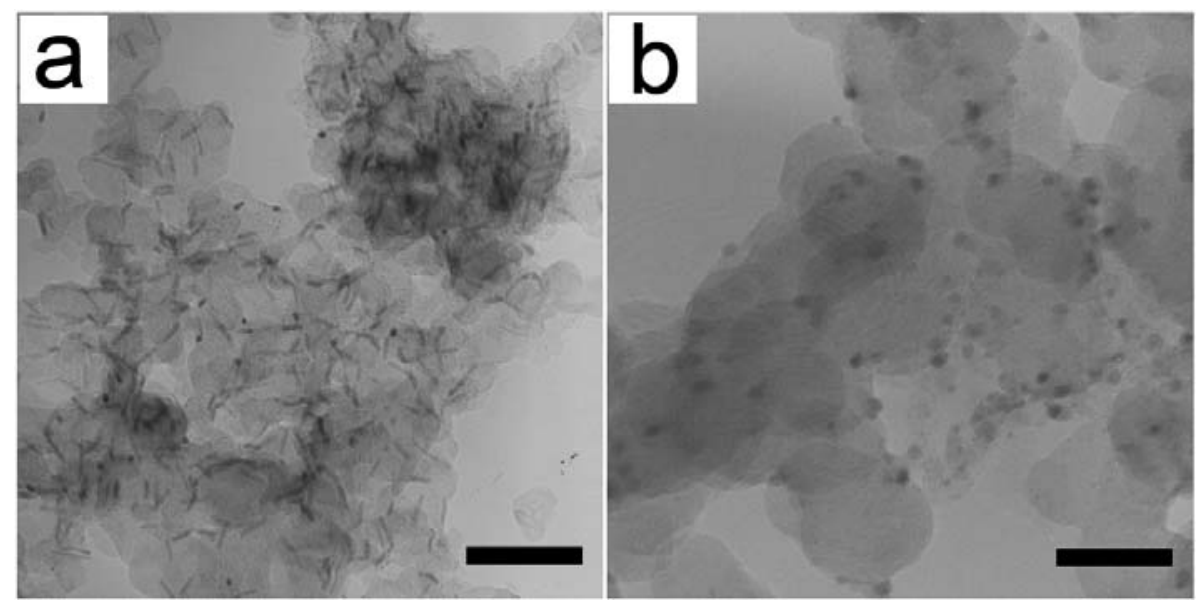

Figure S7. TEM images of PtPb nanorods (a) supported on carbon black and (b) after treated in air plasma for $30 \mathrm{~min}$ and then at $600{ }^{\circ} \mathrm{C}$ for $2 \mathrm{~h}$ under an atmosphere of $5 \%(\mathrm{v} / \mathrm{v})$ hydrogen in argon. The scale bars are $100 \mathrm{~nm}$. 